\title{
DEVELOPMENT AND VALIDATION OF NEW RP-HPLC METHOD FOR QUANTITATIVE ESTIMATION OF GUAIFENESIN IN TABLET DOSAGE FORM
}

\author{
Raja Abhilash Punagoti*, Nurahmed Seid Getaw and Rita Mourya \\ Department of Pharmaceutical Chemistry, School of Pharmacy, College of Medicine and Health Sciences, \\ University of Gondar, Gondar 196, Ethiopia \\ ${ }^{*}$ E-mail: drrajaabhilash@gmail.com \\ Tel.: +251985074711 .
}

Received: Oct 20,2019 / Revised: Nov 25, 2019 / Accepted: Nov 26, 2019

\begin{abstract}
A novel very rapid, sensitive, reverse phase high performance liquid chromatography (RP-HPLC) technique was developed for the quantitative estimation of Guaifenesin in bulk and tablet dosage form. The developed HPLC method has several advantages over reported HPLC methods with respect to speed, solvent consumption, resolution and cost of analysis. It was resolved by using a mobile phase of Phosphate buffer:Acetonitrile in the ratio $60: 40 \mathrm{v} / \mathrm{v}$ at a flow rate of $1 \mathrm{ml} / \mathrm{min}$ using UV Visible detector at the wavelength of $232 \mathrm{~nm}$ for quantification. Efficient separation was achieved for Guaifenesin on Cosmosil C18 column (100 $\times 2.1 \mathrm{~mm}, 5 \mu \mathrm{m})$. The retention time of Guaifenesin was 2.783 min. The calibration graphs were linear and the method showed excellent recovery for tablet dosage form. The developed method was validated according to the International Conference on Harmonization (ICH) guidelines with respect to linearity, accuracy, precision, specificity and robustness.
\end{abstract}

Key words: Guaifenesin, HPLC, New method development, Validation, ICH guidelines.

\section{INTRODUCTION}

Guaifenesin is chemically known as is (+)-3-(2methoxyphenoxy)-propane-1, 2-diol, is a widely used expectorant and in treatment of coughing. It is useful for the symptomatic relief of respiratory conditions (Smith et al 2008; Albrecht et al 2017). Its empirical formula is $\mathrm{C}_{10} \mathrm{H}_{14} \mathrm{O}_{4}$, which corresponds to a molecular weight of 198.21. The structure of Guaifenesin is shown in Figure 1. It is a white or slightly gray crystalline substance with a slightly bitter aromatic taste. Guaifenesin is used to relive chest congestion.

High Performance Liquid Chromatography (HPLC) method is one of the widely used methods for simultaneous determination of drugs (Jain et al 2012; Banerjee and Vasava, 2013; Patwari et al 2014; Shrestha et al 2016).<smiles>COc1ccccc1OC[C@@H](O)CO</smiles>

Fig. 1. Chemical structure of Guaifenesin

Several HPLC methods were reported for simultaneous determination of Guaifenesin and other expectorants in pharmaceutical preparations (Gudipati et al 1991; Demian, 1993; Suzen et al 1999; Shuhan et al 2005; Suma et al 2013; Sagathiya and Bagada, 2014). The LCMS method was also reported for quantification of Guaifenesin in human plasma (Andrew et al 2011). The UV method has been reported for Guaifenesin (Banker et al 2013) and only two 
HPLC methods were related for individual estimation of Guaifenesin (Ahmed and Lottfi, 2013; Reddy et al 2011). The reported HPLC methods were more time consuming, complex mobile phase mixtures, use high flow rate of analysis, lack of sensitivity and peak symmetry. It is, therefore, felt necessary to develop a new rapid method for the determination of Guaifenesin by HPLC method.

Hence, a reproducible RP-HPLC method was developed for the quantitative determination of Guaifenesin tablets by using Cosmosil C18 column $(100 \times 2.1 \mathrm{~mm}, 5 \mu \mathrm{m})$ HPLC column. The proposed method was validated as per the guidelines suggested by ICH (Punagoti and Jupally, 2014).

\section{MATERIALS AND METHODS \\ Reagents}

Guaifenesin Working Standard was procured from Aurobindo Laboratories, Hyderabad, India. Commercially available Guaifenesin was purchased from local pharmacy. Acetonitrile HPLC Grade and Ortho-phosphoric acid AR grade were obtained from Merck Chemicals, Mumbai. Water was prepared by using Millipore Milli Q Plus water purification system.

\section{Chromatographic conditions}

Chromatography separation was performed on LC Solution HPLC with UV detector. The output signal was monitored and processed using Chrom-work station HPLC V4.0 software. The chromatographic column used Cosmosil C18 $(100 \times 2.1 \mathrm{~mm}, 5 \mu \mathrm{m})$. The mobile phase of phosphate buffer:acetonitrile in the ratio 40:60 $v / v$ at a flow rate of $1.0 \mathrm{ml} / \mathrm{min}$. The detection was monitored at the wavelength of $232 \mathrm{~nm}$. The injection volume was $20.0 \mu \mathrm{l}$ and the chromatographic runtime of $8 \mathrm{~min}$ was used.

\section{Preparation of solutions}

Preparation of Phosphate buffer

Seven grams of Potassium dihydrogen phosphate was weighed into a $1000 \mathrm{ml}$ beaker, dissolved and diluted to $1000 \mathrm{ml}$ with millipore water. Finally, adjusted the $\mathrm{pH}$ to 4.0 with orthophosphoric acid.

\section{Preparation of mobile phase}

A mixture of above buffer $400 \mathrm{ml}(40 \%)$ and 600 $\mathrm{ml}$ of Acetonitrile (60\%) was mixed and degassed in ultrasonic water bath for $5 \mathrm{~min}$ followed by filtration through $0.45 \mu$ filter under vacuum filtration.

\section{Preparation of the Guaifenesin standard and sample solution}

Standard solution preparation

A sample equivalent to $10 \mathrm{mg}$ of Guaifenesin working standard was accurately transferred into a $10 \mathrm{ml}$ volumetric flask. $1 \mathrm{ml}$ of diluent is taken and added $9 \mathrm{ml}$ of mobile phase then, sonicated to dissolve it completely and the volume was made up to the mark with the same solvent (Stock solution). Further, $1 \mathrm{ml}$ of the above stock solution was pipetted out into a 10 $\mathrm{ml}$ volumetric flask and diluted up to the mark with diluents. Mixed well and filtered through $0.45 \mu \mathrm{m}$ filter.

\section{Sample solution preparation}

The sample equivalent to $10 \mathrm{mg}$ of Guaifenesin was accurately transferred into a $10 \mathrm{ml}$ volumetric flask. About $1 \mathrm{ml}$ of diluent was added and sonicated to dissolve it completely and the volume was made up to the mark with diluent. Mixed well and filtered through $0.45 \mu \mathrm{m}$ filter. Further, pipette $1 \mathrm{ml}$ of the above stock solution was pipetted out into a $10 \mathrm{ml}$ volumetric flask and diluted up to mark. Mixed well and filtered through $0.45 \mu \mathrm{m}$ filter.

\section{Method validation}

Precision

The precision of the method was evaluated by carrying out five independent assays of test sample against a qualified reference standard and the \% RSD of assay was calculated (\% RSD should not be more than $2 \%$ ).

\section{Intermediate Precision/Ruggedness \\ Intra-day precision}

The precision of the assay method was evaluated by carrying out five independent assays of Guaifenesin (50, 100, 150\% i.e. 5.0, 7.5, 10.0 $\mu \mathrm{g} / \mathrm{ml}$ ) test samples against qualified reference standard. The percentage of RSD of five assay values was calculated.

\section{Intermediate precision (inter-day)}

Different analysts from the same laboratory and by using different column of same brand evaluated the intermediate precision of the method. This was performed by assaying the five samples of Guaifenesin against qualified reference standard. The percentage of RSD of five assay values was calculated. The \% RSD for the area of five replicate injections was found to be within the specified limits (\% RSD should not be more than $2 \%$ ). 


\section{Accuracy}

Recovery of the assay method for Guaifenesin was established by three determinations of test sample using tablets at $50 \%, 100 \%$ and $150 \%$ of analyte concentration. Each solution was injected thrice $(n=3)$ into HPLC system and the average peak area was calculated from which Percentage recoveries were calculated. (\% Recovery should be between 98.0 to $102.0 \%$ ).

\section{Linearity}

Test solutions were prepared from stock solution at 5 concentration levels $(20,30,40,50$, and $60 \mu \mathrm{g} / \mathrm{ml}$ ). The peak area $v s$ concentration data treated by least square linear regression analysis. (Correlation coefficient should be not less than 0.999).

\section{Limit of Detection (LOD) and Limit of Quantification (LOQ)}

LOD and LOQ were determined at signal to noise ratios of $3: 1$ and 10:1, respectively by injecting series of dilute solutions with known concentrations.

\section{Robustness}

To prove the reliability of the analytical method during normal usage, some small but deliberate changes were made in the analytical method (e.g. flow rate, column temperature, and mobile phase composition). Changes in the chromatographic parameters (i.e. theoretical plates and the tailing factor) were evaluated for the studies.

\section{RESULTS}

\section{Method development}

Different chromatographic conditions were experimented to achieve better efficiency of the chromatographic system. Parameters such as mobile phase composition, wavelength of detection, column, column temperature, $\mathrm{pH}$ of mobile phase, and diluents were optimized. Several proportions of buffer and solvents (water, methanol and acetonitrile) were evaluated in order to obtain suitable composition of the mobile phase. Choice of retention time, tailing, theoretical plates, and run time were the major tasks while developing the method. Buffers like sodium dihydrogen orthophosphate, dipotassium hydrogen orthophosphate, and disodium hydrogen orthophosphate did not yield desired results. Use of ion pair reagents also did not yield the expected peak. At 40:60 (buffer: solvent) ratio of the mobile phase, a perfect peak was eluted. Thus, the mobile phase ratio was fixed at 40:60 (buffer: solvent) in an isocratic mobile phase flow rate. The typical chromatogram obtained for Guaifenesin from final HPLC conditions are depicted in Figure 2.

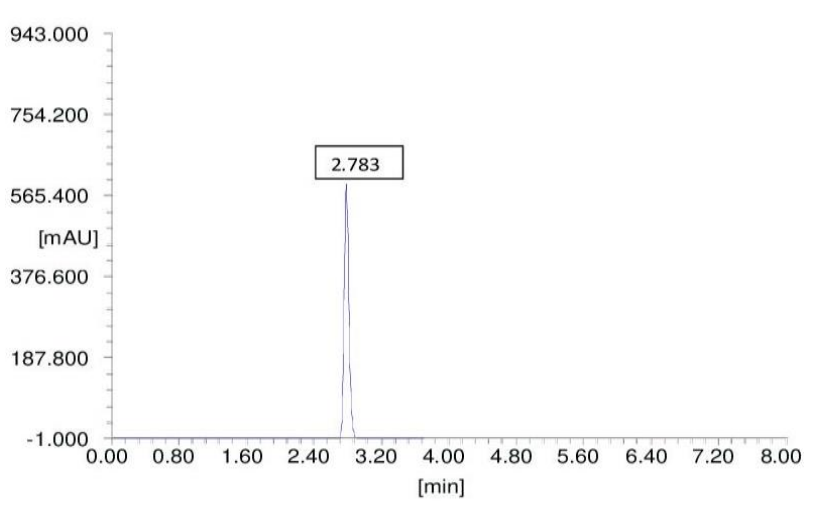

Fig. 2. Typical chromatogram of Guaifenesin by proposed method

\section{Method validation}

Based on International Conference on Harmonization (ICH) guidelines, the method is validated with regard to system suitability, linearity, accuracy, precision, LOD, LOQ, robustness and sensitivity as follows:

\section{System suitability}

The system suitability results for the proposed HPLC method are: Tailing factor obtained from the standard injection is 1.28 . Theoretical plates obtained from the standard injection is 11105.3. The results proved that the optimized HPLC method fulfils these requirements within the USP accepted limits indicated in the 'Experimental' section.

\section{Precision}

The \% RSD of Guaifenesin assay during the method precision was found to be $1.73 \%$, indicating good precision of the method. The results are summarized in Table 1.

Table 1. Results of precision

\begin{tabular}{|c|c|}
\hline Injection & Area \\
\hline Injection-1 & 70131.8 \\
\hline Injection-2 & 70650.7 \\
\hline Injection-3 & 71284.2 \\
\hline Injection-4 & 72547.3 \\
\hline Injection-5 & 72653.8 \\
Injection-6 & 73241.6 \\
\hline Average & 71751.57 \\
\hline Standard deviation & 1242.691 \\
\hline \% RSD & $1.73 \%$ \\
\hline
\end{tabular}


Limits of detection and quantification ( $L O D / L O Q)$ LOD and LOQ for Guaifenesin were 0.01 and 0.05 $\mu \mathrm{g} / \mathrm{ml}$, respectively. Since the LOQ and LOD values of Guaifenesin are achieved at a very low level, this method can be suitable for cleaning validation in the pharmaceutical industry.

\section{Accuracy}

The percentage recovery of Guaifenesin samples ranged from $98.8 \%$ to $101.4 \%$ and the mean recovery is $99.96 \%$, showing the good accuracy of the method opted. The result is shown in Table 2.

Table 2. Results of accuracy

\begin{tabular}{|c|c|c|c|c|c|}
\hline $\begin{array}{c}\text { \% Concentration } \\
\text { (at specification level) }\end{array}$ & Area & $\begin{array}{c}\text { Amount added } \\
\text { (mg) }\end{array}$ & $\begin{array}{c}\text { Amount found } \\
\text { (mg) }\end{array}$ & $\begin{array}{c}\text { \% } \\
\text { Recovery }\end{array}$ & $\begin{array}{c}\text { Mean } \\
\text { Recovery }\end{array}$ \\
\hline $50 \%$ & 75587.167 & 5.0 & 5.0 & $99.95 \%$ & \multirow{2}{*}{$99.96 \%$} \\
\hline $100 \%$ & 161756.43 & 7.5 & 7.5 & $99.98 \%$ & \multirow{2}{*}{ (10.5 } \\
\hline $150 \%$ & 208555.8 & 10.0 & 10.2 & $99.95 \%$ & \\
\hline
\end{tabular}

\section{Linearity}

The linearity of the calibration plot for the method was obtained over the calibration ranges tested, i.e. $50-90 \mu \mathrm{g} / \mathrm{ml}$ for three times, and the correlation coefficient obtained was 0.999 , thus indicating excellent correlation between peak areas and concentrations of the analyte.

\section{Robustness}

In all the deliberately varied chromatographic conditions in the concentration range for the evaluation of robustness is $10-50 \mu \mathrm{g} / \mathrm{ml},(n=3)$. It can be concluded that the variation in flow rate and the variation in $10 \%$ organic composition do not affect the method significantly.

Hence, it indicates that the method is robust even by change in the flow rate $\pm 10 \%$ and change in the mobile phase $\pm 10 \%$. The results are summarized in Table 3.

Table 3. Results of robustness

\begin{tabular}{|c|c|c|}
\hline Chromatographic changes & USP Plate Count & USP Tailing \\
\hline Flow rate (ml/min) & & \\
0.8 & 10478.5 & 1.29 \\
$1.0^{*}$ & 10297.33 & 1.35 \\
1.2 & 9898.94 & 1.36 \\
\hline Change in organic composition & & \\
in the mobile phase & & 1.28 \\
10\% less & 9350.33 & 1.35 \\
40:60 (Buffer:acetonitrile) ${ }^{*}$ & 10297.33 & 1.28 \\
10\% more & 10044.49 & 1.9 \\
\hline UV wavelength(nm) & 8680.99 & 1.29 \\
230 & 12965.45 & 1.26 \\
\hline $232^{*}$ & 8273.24 & \\
234 &
\end{tabular}

*optimized parameters

Application of the developed method to commercial Guaifenesin tablets

When the developed method was used to analyze a commercial brand of Guaifenesin tablet formulation, the mean recovery of five replicates was $99.96 \%$ with \% RSD of 1.73 . The $\%$ recovery value indicates non-interference from the excipients present in the dosage form.

\section{DISCUSSION}

\section{Method development and optimization}

The main aim of the developed method was to achieve separation and quantification of Guaifenesin using an isocratic mobile phase with
HPLC system. Developing a HPLC method was to reduce the run time of the method and solvent consumption for routine analysis such as assay, dissolution and content uniformity during quality assurance. Detection of Guaifenesin was adequate at $232 \mathrm{~nm}$. The initial trial was conducted using HPLC and chromatographic separation was obtained on C18 column $(100 \times$ $2.1 \mathrm{~mm}$, particle size $5 \mu \mathrm{m}$ ). The mobile phase was optimized in the ratio of Phosphate buffer:Acetonitrile in the ratio 40:60\% $v / v$ at a flow rate of $1 \mathrm{ml} / \mathrm{min}$. While developing the HPLC method, basic chromatographic conditions such as the column, solvents and UV detection 
employed in the HPLC method were taken into account. In selecting the HPLC column, its stability at the lower $\mathrm{pH}$ was taken into consideration to preserve the long life of the column.

Most commercial C18 columns are not stable at lower $\mathrm{pH}$ on the longer run, thus shortening their life span. Column Cosmosil C18 (100 × 2.1 $\mathrm{mm}, 5 \mu \mathrm{m}$ ) was found to be more suitable and stable at this $\mathrm{pH}$. The peak was sharp and acceptable. The flow rate also is scaled down from 2.0 to $1.0 \mathrm{ml} / \mathrm{min}$. When these operating conditions were applied to the developed method, a satisfactory peak was achieved for Guaifenesin, which eluted at around $2.783 \mathrm{~min}$

\section{REFERENCES}

Ahmed NR, Lottfi ASN. High performance liquid chromatographic method for the determination of Guaifenesin in pharmaceutical syrups and in environmental samples. Baghdad Sci. J. 2013; 10(3):101422. [DOI: 10.21123/bsj.2013.10.3.1014-1022]

Albrecht HH, Dicpinigaitis PV, Guenin EP. Role of Guaifenesin in the management of chronic bronchitis and upper respiratory tract infections. Multidiscip. Respir. Med. 2017;12:31 [DOI: 10.1186/s40248-017-0113-4].

Andrew AA, Sridharan D, Thenmzohi A, Palanivelu M. Bioanalytical method development and validation of Guaifenesin in human plasma by liquid chromatography coupled with tandem mass spectroscopy. Int. J. Pharm. Pharm. Sci. 2011;2(3):73-82.

Banerjee SK, Vasava NM. Simultaneous estimation of Amlodipine and Rosuvastatin in combined bulk forms by RP-HPLC using ultraviolet detection. Bull. Pharm. Res. 2013;3(1):29-33.

Bankar AA, Lokhande SR, Sawant RL, Bhagar AR. Spectrophotometric estimation of Guaifenesin and Salbutamol in pure and tablet dosage form by using different methods. Der Pharm. Chem. 2013;5(3):92-7.

Demian I. High-performance liquid chromatography (HPLC) chiral separations of Guaifenesin , Methocarbamol, and Racemorphan. Chirality 1993;5(4):238-40. [DOI: 10.1002 /chir.530050409]

Gudipati RM, Wallace JE, Stavchansky SA. High performance liquid chromatography determination of Guaifenesin in dog plasma. Anal. Lett. 1991;24(2):265-74. [DOI: 10.1080 /00032719108052902]

Jain N, Jain R, Jain DK, Jain SK. RP-HPLC method for simultaneous estimation of Esomeprazole magnesium and Domperidone in a tablet dosage form. Bull. Pharm. Res. 2012;2(3):134-9.

Patwari A, Dabhi M, Rathod I, Desai U, Suhagia BN, Sharma M. Simultaneous determination of Ofloxacin and Cefixime in combined tablet dosage form by HPLC and absorbance correction method. Bull. Pharm. Res. 2014;4(3):112-7.

Punagoti RA, Jupally VR. Development and Validation of RP- giving a total run time of $8 \mathrm{~min}$.

\section{CONCLUSION}

The new, isocratic RP-HPLC method proved to be simple, linear, precise, accurate, robust, rugged and rapid. The developed method was capable of giving faster elution, maintaining good separation more than that achieved with conventional HPLC. The short retention time of $2.783 \mathrm{~min}$ allows the analysis of a large number of samples in a short period of time and is therefore more cost-effective for routine analysis in the pharmaceutical industries. It is suitable for rapid and accurate quality control of Guaifenesin in tablet formulations.

HPLC method for simultaneous determination of Ritonavir and Lopinavir in a combined dosage form. Anal. Chem.: An Indian J. 2014;14(3):88-92.

Reddy SP, Babu KS, Kumar N, Sekhar YV. Development and validation of stability indicating the RP-HPLC method for the estimation of related compounds of Guaifenesin in pharmaceutical dosage forms. Pharm. Methods 2011;2(4):229-34. [DOI: 10.4103/2229-4708.93391]

Sagathiya K, Bagada H. Development and validation of RPHPLC and HPTLC method of analysis for simultaneous estimation of Ambroxol $\mathrm{HCl}$, Dextromethorphan $\mathrm{HBr}$ and Guaifenesin in pharmaceutical cough cold preparation and statistical comparison of developed methods. Int. J. Pharm. Pharm. Sci. 2014; 6(2):312-6.

Shrestha DM, Srinivasa Rao T, Sreedhar C, Akkamma HG, Bharadwaja Reddy G, Yadav PK. Development and validation of new analytical method for the simultaneous estimation of Naproxen and Esomeprazole in bulk and pharmaceutical formulation. Bull. Pharm. Res. 2016;6(1):28-35. [DOI: 10.21276/bpr.2016.6.1.5]

Shuhan T, Gie R, Qian L, Zhenmin D, Hwaiqing Z. Simultaneous determination of the contents of the three components in Guaifenesin, Pseudoephedrine $\mathrm{HCl}$ and Dextromethorphan hydrobromide capsules by HPLC. Shenyang Yoake Daxue Xuebao 2005;22:119-21.

Smith SM, Schroeder K, Fahey T. Over-the-counter medications for acute cough in children and adults in ambulatory settings. Cochrane database Syst. Rev. 2008;1:CD001831.

Suma CH, Vasantha K, Prabhakar Reddy A, Ajay Kumar CH, Nalluri BN. Simultaneous estimation of Phenylephrine hydrochloride and Guaifenesin in bulk drug and pharmaceutical dosage forms by RP-HPLC-PDA method. J. Chem. Pharm. Res. 2013;5(8):188-94.

Suzen S, Akay C, Cevheroglu S. Simultaneous determination of Guaifenesin and Codeine phosphate in tablets by highperformance liquid chromatography. Il Farmaco 1999;54(10):705-9. [DOI: 10.1016/S0014-827X(99)0008 6-5] 